\title{
INCLUSÃO EM EDUCAÇÃO: REFLEXÕES SOBRE DEMOCRACIA, SOCIEDADE E ESCOLA CONTEMPORÂNEA À LUZ DA TEORIA CRÍTICA
}

\author{
Inclusion in education: reflections on democracy, society and contemporary school \\ in the light of Critical Theory
}

\section{Inclusión en la educación: reflexiones sobre la democracia, la sociedad y la escuela contemporánea a la luz de la Teoría Crítica}

\author{
Patrícia Ferreira de Andrade* \\ Andressa Silva Pereira** \\ Allan Rocha Damasceno***
}

\begin{abstract}
Resumo
A partir da década de noventa, em esfera nacional e internacional, a inclusão em educação se fortalece com inúmeras Políticas públicas educacionais que fundamentam a tríade: acesso, permanência e sucesso escolar. Para isso, os sistemas de ensino precisam se (re) organizar para a consolidação de espaços democráticos. Nessa perspectiva, vale o questionamento: será que todos desejam uma educação democrática? Assim, este estudo objetivou refletir/debater a escola e a sociedade à luz da Teoria Crítica, tendo como lente analítica o pensamento do filósofo Theodor Adorno, e de seus comentadores, de modo que problematizamos as amarras da sociedade, pois nos damos conta que a estrutura socioeconômica autoritária que vivemos obstaculiza a emancipação e, por conseguinte, a construção de escolas que celebrem as diferenças. Debruçando-nos sob tal ótica, percebemos que a inclusão em educação é a afirmação de um projeto educacional democrático, que reconhece as demandas específicas de cada estudante, trabalhando numa pedagogia onde a escola é quem deve adaptar-se ao estudante e nunca o inverso.
\end{abstract}

PALAVRAS-CHAVE: Inclusão. Escola. Teoria Crítica.

\footnotetext{
* Doutoranda em Educação pelo PPGEduc (Programa de Pós-Graduação em Educação Contextos Contemporâneos e Demandas Populares) da Universidade Federal Rural do Rio de Janeiro (UFRuralRJ). Professora I Educação Especial do Município de Duque de Caxias/RJ. E-mail: pat.fandrade@gmail.com ${ }^{* *}$ Mestre em Educação pelo PPGEduc (program de Pós-graduação em Educação, Contextos Contemporâneos e Demandas Populares) da Universidade Federal Rural do Rio de Janeiro (UFRuralRJ). Professora de Educação Especial do município de Mesquita/RJ. E-mail: andressasp07@hotmail.com *** Mestre e Doutor em Educação pela Universidade Federal Fluminense (UFF). Pós-doutorado na Universidade Federal do Paraná (UFPR). Professor Associado do Instituto de Educação da Universidade Federal Rural do Rio de Janeiro (UFRuralRJ)- Departamento de Educação do Campo, Movimentos Sociais e Diversidade (DECMSD). Coordena o Laboratório de Estudos e Pesquisas em Educação, Diversidade e Inclusão (LEPEDI). Membro do Observatório Estadual de Educação Especial do Rio de Janeiro (OEERJ), vinculado ao Observatório Nacional de Educação Especial (ONEESP). Atua no Programa de Pós-graduação em Educação, Contextos Contemporâneos e Demandas Populares (PPGEduc) na linha de pesquisa "Desigualdades Sociais e Políticas Educacionais" e no Programa de Pósgraduação em Educação Agrícola (PPGEA) na linha de pesquisa "Gestão e Educação do Ensino Agrícola", ambos da UFRuralRJ. Membro da Associação Brasileira de Pesquisadores em Educação Especial (ABPEE). Endereço profissional: Instituto de Educação - UFRJ, sala 09 - BR 465, km 7 , Seropédica, Rio de Janeiro, 23890000. Contato profissional: (21) 2682-1814. E-mail: lepediufrrj@ hotmail.com Orcid: https://orcid.org/0000-0003-0577-805X
} 


\begin{abstract}
From the 1990s onwards, nationally and internationally, inclusion in education has been strengthened by numerous educational public policies that underlie the triad: access, permanence and academic success. For this, the education systems need to (re) organize themselves for the consolidation of democratic spaces. In this perspective, the question is worth asking: does everyone want a democratic education? In this sense, this study aims to reflect / debate the school and society in the light of Critical Theory, through the thoughts of the philosopher Theodor Adorno and his commentators, so that it helps us to observe the bonds of society, in an emancipatory perspective, because we give ourselves he says that the authoritarian socioeconomic structure that we live in, hinders emancipation, and then the construction of schools that embrace differences. Looking at it from this perspective, we realize that inclusion in education is geared towards a democratic educational project, which aims to respond to the specific demands of each student, working in a pedagogy where the school is the one who must adapt to the student and never the reverse.
\end{abstract}

KEYWORDS: Inclusion. School. Critical Theory.

\title{
Resumen
}

A partir de la década de 1990, a nivel nacional e internacional, la inclusión en la educación se ve reforzada por numerosas políticas educativas públicas que subyacen a la tríada: acceso, permanencia y éxito académico. Para esto, los sistemas educativos necesitan (re) organizarse para la consolidación de espacios democráticos. En esta perspectiva, vale la pena preguntarse: ¿todos quieren una educación democrática? En este sentido, este estudio tiene como objetivo reflejar / debatir la escuela y la sociedad a la luz de la teoría crítica, a través de los pensamientos del filósofo Theodor Adorno y sus comentaristas, de modo que nos ayude a observar los lazos de la sociedad, en una perspectiva emancipadora, porque nos entregamos Él dice que la estructura socioeconómica autoritaria en la que vivimos, dificulta la emancipación, y luego la construcción de escuelas que abrazan las diferencias. Mirándolo desde esta perspectiva, nos damos cuenta de que la inclusión en la educación está orientada hacia un proyecto educativo democrático, que tiene como objetivo responder a las demandas específicas de cada estudiante, trabajando en una pedagogía donde la escuela es la que debe adaptarse al estudiante y nunca al revés.

PALABRAS CLAVE: Inclusión. Escuela. Teoría crítica

\section{INTRODUÇÃO}

As marcas do processo de globalização e dos princípios da hegemonia do neoliberalismo em desenvolvimento no mundo atual, impõem à educação contemporânea a submissão do controle do capital. Dessa forma, o modelo neoliberal implantado nos países capitalistas avançados se expande por toda a parte (ANDERSON, 1995).

O neoliberalismo conseguiu muitos dos seus objetivos, criando sociedades marcadamente mais desiguais, embora não tão desestatizadas como queria. Política e ideologicamente, todavia, o neoliberalismo alcançou êxito num grau com o qual seus fundadores originalmente jamais sonharam, disseminando a simples ideia de que não há alternativas para os seus 
princípios, que todos, seja confessando ou negando, têm de adaptar-se a suas normas (ANDERSON, 1995, p. 22-23).

O neoliberalismo retoma os princípios do capitalismo liberal do século XIX, o que demarca uma reação teórica e política contra o estado intervencionista e de bemestar social (ANDERSON, 1995). É uma política econômica que se efetiva pelos mecanismos de mercado. Assim, a hegemonia do capital atua em suas ações reguladoras e redistributivas nas instâncias da sociedade, materializando-se em diferentes formas heterodoxas de imposição de poder na sociedade.

Nesse sentido, somos provocados a pensar sobre a educação que está sendo estabelecida nos moldes dos mecanismos da produção do capital, presentes no contexto social da sociedade contemporânea. Assim, a reflexão crítica no cenário social e educacional revela o quanto os profissionais da educação necessitam estar cônscios de suas práticas pedagógicas nas instâncias escolares, respeitando a diversidade humana no embate ao fluxo anticivilizatório que se estrutura sob a forma de preconceitos, estereótipos, exclusão e segregação que engendram a escola e a sociedade no modus operandi atual. Assim, tecemos algumas considerações que permitem compreender a visão vigente do capitalismo e sua consequente globalização operante, tal como revelam Horkheimer e Adorno (1985, p. 184):

Com a propriedade burguesa, a cultura também se difundiu. Ela havia empurrado a paranóia para os recantos obscuros da sociedade e da alma. Mas como a real emancipação dos homens não ocorreu ao mesmo tempo que o esclarecimento do espírito, a própria cultura ficou doente. Quanto mais a realidade social se afastava da consciência cultivada, tanto mais esta se via submetida a um processo de reificação. A cultura converteu-se totalmente numa mercadoria, difundida como uma informação, sem penetrar nos indivíduos dela informados [...] O pensamento reduzido ao saber é neutralizado e mobilizado para a simples qualificação nos mercados de trabalho específicos e para aumentar o valor mercantil da personalidade. Assim naufraga essa auto-reflexão do espírito que se opõe à paranóia.

Em vista disso, o capitalismo tem um caráter extremamente competitivo (THERBORN, 1995) e situa o mercado como centro regulador econômico (SANTOS, 1995; MORAES \& DUAYER, 1995). Deste modo, a organização econômica do capital e do lucro controlam todas as esferas da vida humana o que, por sua vez, permite uma liberdade econômica, ou seja, um capitalismo competitivo que é força motriz para a liberdade política, onde ambos exercem o controle um sobre o outro. Essas configurações também derivam de forma particular sobre o campo da educação, em seu papel nuclear relativo às mudanças econômicas, políticas e societárias. Quanto a isso também corrobora Adorno (1996, p.01) quando afirma que "A tarefa atribuída a tais indivíduos dentro de uma sociedade caracterizada pela divisão do trabalho poderia, realmente, ser questionada; eles mesmos poderiam muito bem estarem deformados por ela. Mas, eles também foram formados por ela ${ }^{1}$."

Segundo Damasceno (2015), na obra "Dialética do Esclarecimento", há uma crítica da civilização técnica e da lógica cultural do sistema capitalista, cujos autores

\footnotetext{
${ }^{1}$ Publicado na revista Telos, por Wes Blomster 35, Spring 1978, p. 165-168 e em Bernstein, J.J. Adorno: the Culture Industry, Londres: New Fetter Lane, 1996. Tradução de Newton Ramos-de-Oliveira e revisão de Antonio Álvaro Soares Zuin, Fábio Akcelrud Durão e Paula Ramos de Oliveira. Texto encontrado no endereço eletrônico: <http://www.unimep.br/teoriacritica/index.php?fid=116\&ct=10275> - Acesso em: 28/03/2020.
} 
Horkheimer e Adorno (1985, p.114-115) enfatizam a finalidade dessas concepções apenas no progresso técnico, denominada por eles de indústria cultural. Portanto:

\begin{abstract}
Na opinião dos sociólogos, a perda do apoio que a religião objetiva fornecia, a dissolução dos últimos resíduos pré-capitalistas, a diferenciação técnica e social e a extrema especialização levaram a um caos cultural [...] Pois a cultura contemporânea confere a tudo um ar de semelhança. [...] $\mathrm{O}$ fato de que milhões de pessoas participam dessa indústria imporia métodos de reprodução que, por sua vez, tornam inevitável a disseminação de bens padronizados para a satisfação de necessidades iguais.
\end{abstract}

Dessa forma, há uma configuração alienante marcada pela barbárie, no qual a democracia é ocultada, visto que, os mecanismos de exclusão social na manifestação do preconceito e segregação são aumentados em prol da sustentabilidade do poder. Nesse sentido, a visão da burguesia industrial é a própria denominação da indústria cultural, cuja inserção no mundo provocou ações metamórficas na estrutura social e, consequentemente, nas relações humanas.

Ante estas problematizações, não se pode refletir as questões referentes às políticas educacionais sem contextualizar o papel da educação sob a ótica vigente do capital. Esse entendimento significa a compreensão da especificidade educacional em interlocução com o viés histórico, político e formativo nas diversas instâncias na contemporaneidade.

A partir da década de noventa do século XX, houve um novo movimento no sistema educacional brasileiro: emergia o movimento da inclusão em educação. Nesse sentido, discorrer sobre a relevância das Políticas públicas de inclusão escolar para a afirmação de uma escola acolhedora é caminhar rumo à democratização do ensino e, quiçá, da sociedade. A inclusão em educação preconiza que todos os estudantes devem aprender juntos, na perspectiva da construção de processos de ensino e aprendizagem que se voltem para as diferentes demandas dos estudantes.

$\mathrm{Na}$ atualidade vem crescendo o número de escolas que se dizem inclusivas ${ }^{2}$, ou seja, que atendem estudantes público-alvo da educação especial ${ }^{3}$. Dessa forma, torna-se indispensável investigar que educação tem sido afirmada nas escolas ditas inclusivas, pois pensar acerca da inclusão em educação, bem como seus desafios e possibilidades, é corroborar para a implementação de instituições escolares democráticas, onde cada estudante/indivíduo seja reconhecido em sua singularidade. Conforme Pereira destaca (2014, p.37):

A educação nos moldes segregativos aniquila a diferença, vivificando o preconceito e reforçando a estereotipia do pensamento no espaço escolar e na sociedade. Estudar e estar com outros estudantes que não possuem deficiência permite o enfrentamento dos preconceitos e a compreensão da diferença como essência humana.

\footnotetext{
${ }^{2} E ́$ oportuno esclarecer que em algumas instituições escolares, muitas vezes utilizam o adjetivo "inclusiva", esquecendo que a inclusão em educação não se restringe ao atendimento de estudantes público-alvo da Educação Especial, mas, também, a diversidade de um modo geral, como por exemplo, em relação à gênero, religião, etnia, orientação sexual, etc., na perspectiva de oferecer educação para todos.

${ }^{3}$ De acordo com a Política Nacional de Educação Especial na perspectiva da Educação Inclusiva (2008), o público-alvo da Educação especial no Brasil é composto pelos alunos com deficiências, transtornos globais do desenvolvimento (TGD) e altas habilidades/superdotação.
} 
Precisamos refletir: para quê Políticas públicas de inclusão em educação? Pensar o "para quê" frente aos objetivos, a priori, educacionais, promove nosso direcionamento, ao nos permitir termos ciência para onde nossa educação está sendo conduzida, nos livrando de práticas inócuas. Desse modo, Adorno (1995, p.140) afirma que:

No instante em que indagamos: "Educacão — para quê?", onde este "para quê" não e mais compreensível por si mesmo, ingenuamente presente, tudo se torna inseguro e requer reflexões complicadas. E, sobretudo, uma vez perdido este "para quê", ele não pode ser simplesmente restituído por um ato de vontade, erigindo um objetivo educacional a partir do seu exterior.

A importância de refletirmos sobre os objetivos educacionais torna-se urgente, pois é necessário irmos além das reproduções que obstaculizam uma educação para o pensar autônomo, compreendendo os mecanismos da produção do capital presentes no contexto social e educacional da sociedade.

\section{A análise da educação sob a égide da teoria crítica da sociedade}

O referencial teórico-analítico deste estudo se fundamenta na Teoria Crítica da Sociedade, com destaque ao pensar de Theodor Adorno, além de outros estudiosos que contribuíram para a análise, afim de compreender as macros/micros influências nos contextos educacionais dos mecanismos do capital/neoliberalismo presentes na sociedade contemporânea. Para tanto, é necessário entender que a Teoria Crítica é uma potente lente na compreensão dos modos de subjetivar, pensar e dialogar sobre as concepções que se produzem na esfera social e educacional.

Convém ressaltar que a teoria é a identidade da solidez para a prática, e que sem a mesma, não há a possibilidade de derivar a experiência em autorreflexão.

Sobre esse aspecto, Adorno (1995a, p. 204-205) esclarece que:

Dever-se-ia formar uma consciência de teoria e práxis que não separasse ambas de modo que a teoria fosse impotente e a práxis arbitrária, nem destruísse a teoria mediante o primado da razão prática, próprio dos primeiros tempos da burguesia e proclamado por Kant e Fichte. Pensar é um agir, teoria é uma forma de práxis; somente a ideologia da pureza do pensamento mistifica este ponto. O pensar tem um duplo caráter: é imanentemente determinado, estringente e obrigatório em si mesmo. Mas, ao mesmo tempo, é um modo de comportamento irrecusavelmente real em meio à realidade. $\mathrm{Na}$ medida em que o sujeito, a substância pensante dos filósofos, é objeto, na medida em que incide no objeto, nessa medida, ele é, de antemão, também prático.

Logo, a Teoria Crítica nos permite construir possibilidades e analisar a natureza do conhecimento produzido ao que está empiricamente dado, pois, "definir é o mesmo que capturar - objetividade, mediante o conceito fixado, algo objetivo, não importa o que isto seja em si” (ADORNO, 1995a, p.182).

Assim como, Horkheimer (1991, p. 69-70), esclarece que:

A teoria em sentido tradicional, cartesiano, como a que se encontra em vigor em todas as ciências especializadas, organiza as experiências à base da formulação de questões que surgem em conexão com a reprodução da vida dentro da sociedade atual [...] a teoria crítica não almeja de forma alguma 
apenas uma mera ampliação do saber, ela intenciona emancipar o homem de uma situação escravizadora.

É nesse movimento que o presente estudo se apresenta, nos permitindo retirar os véus da ignorância e da barbárie, superando o encarceramento da consciência, por conseguinte, se libertando da condição de alienado.

\title{
Dimensões contemporâneas: Auschwitz se faz presente em nossas escolas e sociedade?
}

Para debatermos a democratização do ensino torna-se pertinente recorrermos à exigência de Adorno (1995), quando em seu livro "Educação e Emancipação" inicia o capítulo "Educação após Auschwitz" destacando que a primeira de todas as exigências para a educação é que Auschwitz não se repita.

De forma alguma queremos justificar Auschwitz, pois: "Justificá-la teria algo de monstruoso em vista de toda a monstruosidade ocorrida" (ADORNO, 1995, p.119). Porém, retornar ao passado e tomarmos conhecimento de toda a injustiça que ocorreu nesse e em outros campos de concentração nazistas traz a tona a indignação e o alerta para que Auschwitz não ocorra mais.

Mas, cabe aqui interrogarmos: Auschwitz se faz ou não presente na contemporaneidade? A reflexão acerca deste questionamento não se torna inócua, pois segundo Adorno (1995) a barbárie continuará existindo enquanto persistirem as condições que geram esta regressão. E é exatamente isto que apavora.

De fato, muitos anos se passaram depois desta atrocidade. Todavia, o mundo globalizado não se encontra imune frente a tal barbárie. Já que de acordo com Adorno (1995) a barbárie encontra-se no próprio princípio civilizatório. Sobre Auschwitz:

\begin{abstract}
A reflexão a respeito de como evitar a repeticão de Auschwitz é obscureda pelo fato de precisarmos nos conscientizar desse elemento desesperador, se não quisermos cair presas da retórica idealista. Mesmo assim é preciso tentar, inclusive porque tanto a estrutura básica da sociedade como os seus membros, responsáveis por termos chegado onde estamos, não mudaram nesses vinte e cinco anos. Milhões de pessoas inocentes - e só o simples fato de citar números já e humanamente indigno, quanto mais discutir quantidades - foram assassinadas de uma maneira planejada. Isto não pode ser minimizado por nenhuma pessoa viva como sendo um fenômeno superficial, como sendo uma aberração no curso da história, que não importa, em face da tendência dominante do progresso, do esclarecimento, do humanismo supostamente crescente. O simples fato de ter ocorrido já constitui por si só expressão de uma tendência social imperativa. (ADORNO, 1995, p.120)
\end{abstract}

A responsabilidade de se contrapor a repetição de Auschwitz é evidentemente incontestável para a educação, tendo em vista que instâncias formadoras, como a escola, possuem o poder de formar indivíduos emancipados e resistentes a esta e outras barbáries. Nesse sentido, Adorno (1995) menciona que os culpados não são os assassinados no campo de Auschwitz. Culpados são unicamente os que desprovidos de consciência voltaram contra aqueles seu ódio e sua fúria agressiva.

Retornando ao pensamento de que a barbárie encontra-se no próprio princípio civilizatório, notamos que os nazistas possuíam até mesmo toda uma organização e 
planejamento nos processos de extermínio e nas torturas que realizavam contra os judeus e outros grupos de pessoas que julgavam ser indesejáveis para a Alemanha (homossexuais, ciganos, andarilhos, mendigos, pessoas com deficiência, entre outros).

Ainda dentro desse contexto, os nazistas eram considerados pessoas civilizadas, todavia dotados de uma consciência coisificada que tinha a tendência de coisificar as relações humanas, tratando essas como descartáveis. Portanto, alertamos que a sociedade atual não está imune de tal nível de consciência:

O que outrora era exemplificado apenas por alguns monstros nazistas pode
ser constatado hoje a partir de casos numerosos, como delinquentes juvenis,
lideres de quadrilhas e tipos semelhantes, diariamente presentes no noticiário.
Se fosse obrigado a resumir em uma formula esse tipo de caráter manipulador
- o que talvez seja equivocado embora útil a compreensão - eu o
denominaria de o tipo da consciência coisificada. No começo as pessoas
desse tipo se tornam por assim dizer iguais a coisas (ADORNO, 1995, p.129-
130)

Conforme Max Horkheimer apud Adorno (1995) a tortura é a adaptação controlada e demasiadamente acelerada das pessoas aos coletivos. Mediante isso, fortalecendo a resistência contra os laços que podem gerar Auschwitz, Adorno (1995, p. 127) menciona que: "Considero que o mais importante para enfrentar o perigo que tudo se repita é contrapor-se ao poder cego de todos os coletivos (...)"

Remetendo-nos ao autor (1995), se enquadrar cegamente em coletivos levam os seres ao extremo perigo: dissolverem-se como autodeterminados, cujo combina com a disposição de tratar os outros como sendo uma "massa amorfa"4 .

Romper com o mecanismo da consciência alienada que a massa amorfa pode promover, devido sua orientação uniformizadora, é determinável para a pertinente construção de espaços emancipados, logo livres da barbárie.

Sabemos que o genocídio incentivado por Hitler na Segunda Guerra Mundial é de fato irrecuperável! Mas, para nós é relevante que permaneça o sentimento de repúdio e a mobilização contra movimentos totalitários revestidos de uma consciência coisificada, na qual traduz as pessoas em meras coisas. No que diz respeito à consciência coisificada, Adorno (1995) pensa que é, sobretudo, uma consciência que se defende em relação a qualquer vir-a-ser, frente a qualquer apreensão do próprio condicionamento, impondo como sendo absoluto o que existe de um determinado modo, dessa maneira o rompimento desse mecanismo impositivo seria recompensador.

Ontem milhares de pessoas foram vítimas das atrocidades presente em Auschwitz, devido sua ordem totalitária que desconsiderava a diversidade de um modo geral, segregando e exterminando aqueles que não se enquadravam no padrão de "normalidade", ou seja, havia um "modelo alemão de ser".

Entretanto, tais raízes totalitárias infelizmente ainda são presentes em diversas instâncias, nas quais afirmam a homogeneização de indivíduos. Essa aversão pelo que é diferente impede a construção de uma sociedade democrática, visto que não reconhece a diferença como instância humana.

\footnotetext{
${ }^{4}$ A expreessão"massa amorfa" criada por Adorno reflete o risco que consta em coletivos: ausência de autonomia, de pensar, de reflexão. Ou seja, instâncias que estão atreladas a manipulações em massa que obstaculizam pensamentos críticos e livres
} 
Educar estudantes público-alvo da educação especial, como qualquer outro estudante tendo em vista sua demanda diversificada, é caminhar para a escola e sociedade inclusiva. Para agir na perspectiva de acolher a todos os estudantes/sujeitos precisamos "nadar contra a correnteza" que estrutura a cultura homogeneizadora que marginaliza e exclui grupos minoritários. Assim, nossos esforços se voltam para a afirmação da educação capaz de se contrapor à dominação e à inconsciência social (COSTA, 2015) de segregação dos estudantes, com ou sem deficiência, nas escolas públicas brasileiras e na esfera da sociedade.

Mobilizar-se para uma sociedade, e logo uma escola de/e para todos é responsabilidade posta a todos nós. Adorno (1995) menciona que a ausência de compromissos das pessoas seria culpada pelo que aconteceu, pois é plausível para o entendimento humano evocar compromissos que detenham o que é sádico, destrutivo, desagregador, mediante um enfático: "não deves".

Para a implementação de espaços que acolham a diversidade é indispensável que haja consideração pelo outro. Daí a importância de se refletir sobre a educação como agente de transformação nas instâncias sociais na constituição de uma "consciência verdadeira", que segundo Adorno (1995) se contrapõe e resiste à força da dominação. O filósofo Adorno (1995) esclarece que se as pessoas não fossem profundamente indiferentes em relação ao que ocorre com todas as outras, excetuando os vínculos estreitos e possivelmente por intermédio de alguns interesses concretos, então Auschwitz não aconteceria, as pessoas não teriam aceitado.

Não considerar as demandas específicas de cada estudante, negando seu acesso e permanência escolar é incentivar a barbárie em nossas escolas. Dessa forma, Adorno (1995, p. 157) nos provoca a pensar a barbárie e sua relação direta com a educação:

\begin{abstract}
Quando o problema da barbárie é colocado com toda sua urgência e agudeza na educação, e justamente em instituições como a sua, que desempenha um papel-chave na estrutura educacional da Alemanha hoje, então me inclinaria a pensar que o simples fato de a questão da barbárie estar no centro da consciência provocaria por si uma mudança. Por outro lado, que existam elementos de barbárie, momentos repressivos e opressivos no conceito de educação e, precisamente, também no conceito da educação pretensamente culta, isto eu sou o último a negar. Acredito que, e isso é Freud puro, justamente esses momentos repressivos da cultura produzem e reproduzem a barbárie nas pessoas submetidas a essa cultura.
\end{abstract}

A partir de uma perspectiva crítica, faz se necessário desvelar os limites e as possibilidades para uma educação de/e para todos, pois pensar na possibilidade de uma educação democrática é ir além da mercantilização do ensino, que modela os estudantes de acordo com a lógica capitalista, transformando indivíduos em produtos, excluindo aqueles que não se adaptam ao seu sistema. A concepção da inclusão em educação possui como meta democratizar o ensino, logo trabalhar no sentido de uma educação política suscita a crítica à ideologia vigente (ADORNO, 1995).

Vivemos em uma ordem excludente que impõem padrões de: "como viver", "como ser", "o que fazer", entre outras imposições ditadas pela sociedade dominante, que orientam nossos compromissos e nos fazem seguir seus valores que se reproduzem na formação de "pessoas bem ajustadas" (ADORNO, 1995), ou seja, não-emancipadas. Tal concepção demarca mecanismos que reforçam a sustentação das relações baseada em preconceitos e mecanismos de exclusão, enfatizando o modelo hegemônico consolidado pelo capital. 
Diante disso, a escola como espelha a sociedade também vivencia a barbárie, não considerando, por vezes, as diferenças significativas de seus estudantes. Costa (2005) retrata que a urgência por uma educação democrática parece se constituir alternativa para a superação da diferença como obstáculo para o acesso e permanência de todos os estudantes no ambiente escolar.

A história revela que a pessoa com deficiência, tanto na escola como na sociedade sofreu exclusões, pelo fato de ser diferente, ou seja, por não ajustar-se aos "padrões instituídos de ser". Esses indivíduos eram (são) tratados de forma inferiorizada devido as suas condições atípicas, empregando forte resistência para incluírem-se em sociedade. Dessa medida, Costa (2003, p.28) reflete que:

Todas essas formas de conceber e explicar a deficiência, ao longo do tempo, retratam como as diversas épocas e culturas apresentaram e, sem dúvida, apresentam dificuldades em compreender a diferença, a diversidade entre as pessoas e como lidar com elas.

Notamos assim, que o sujeito com deficiência possui um histórico de fragilidade no contexto político, cultural e social. Entretanto, sabemos que esse cenário vem se transformando, visto o movimento de inclusão em educação, expresso em inúmeras Políticas públicas que legitimam seus direitos não somente nas escolas, mas também na sociedade.

Sawaia (1996, p.120) em seu texto "Identidade - Uma Ideologia Separatista?", ao decorrer sobre eixos identitários destaca que:

O medo do desconhecido, gerando ansiedade, agressão e a busca de sinais identitários, foi suficientemente explorado na literatura. $\mathrm{O}$ homem ao defrontar-se com aquilo que não conhece e domina, perde a capacidade de controle, fica inseguro e muitas vezes desesperado.

Essa repulsa pelo desconhecido, o diferente, foi demasiadamente explorada na literatura explicitando fatos históricos, no qual determinadas identidades eram visualizadas como únicas/verdadeiras, e qualquer outra distinta corria o risco de ser abordada violentamente. Nesta perspectiva, podemos afirmar sem dúvidas, que Auschwitz foi prova disso.

Sob tal assertiva, no capítulo "o que significa elaborar o passado" do frankfurtiano Adorno (1995, p.29), o autor esclarece que:

O desejo de libertar-se do passado justifica-se: não é possível viver à sua sombra e o terror não tem fím quando culpa e violência precisam ser pagas com culpa e violência; e não se justifica porque o passado de que se quer escapar ainda permanece muito vivo. O nazismo sobrevive, e continuamos sem saber se o faz apenas como fantasma daquilo que foi tão monstruoso a ponto de não sucumbir à própria morte, ou se a disposição pelo indizível continua presente nos homens bem como nas condições que os cercam.

Notamos que a barbárie, a violência, ainda se torna viva quando o pensamento enrijecido é manifestado na dimensão contemporânea. Sawaia (1996) auxilia o nosso pensamento quando explica que se pode gerar sofrimentos de diversas ordens e mecanismos defensivos, fundamentalistas e apartheid, sendo um dos mais comuns a busca de parâmetros fixos de identidade, quando no caso, a reflexão é impedida. 
Onde falta a reflexão do próprio objeto, onde falta o discernimento intelectual da ciência, instala-se em seu lugar a frase ideológica, nos termos do deslumbramento daquela infeliz tradição alemã segundo a qual os nobres idealistas vão para o céu e os materialistas ordinários vão para o inferno. (ADORNO, 1995, p. 61)

A superação da "massa amorfa" significa a ruptura com a consciência alienada, que gera o pensamento enrijecido e coisificado, impedindo a reflexão, obstaculizando a construção de uma sociedade de emancipados.

Adorno (1995) nos afirma que uma das características da consciência coisificada é manter-se junto a sua própria fraqueza, procurando justificar-se a qualquer custo. Pois, "é sempre admirável a esperteza de que até os mais obtusos conseguem lançar mão quando se trata de defender malefícios" (ADORNO, 1995, p. 70)

Bader Sawaia (1996) promove nosso conhecimento em relação a esses movimentos identitários perversos quando explica que: "Inúmeros casos dramáticos podem ser citados como exemplo da tríade: identidade/exclusão/violência." (SAWAIA, 1996, p. 121)

Frente a essas considerações e pensando na educação como instância crítica, refletimos que: educar contra a barbárie torna-se fundamental para os profissionais da educação, pois é dentro deste contexto que devemos nos mobilizar no combate do preconceito opressor, que por vezes é o responsável pela exclusão da demanda diversificada que se encontra na escola.

Como vemos, o sistema de ensino precisa se apropriar e implementar as diversas Políticas públicas que fundamentam/legitimam a inclusão em educação, na medida em que essas agem como possibilidade de tornar a escola livre da barbárie, que impede a educação democrática.

\section{CONSIDERAÇÕES FINAIS}

Torna-se necessário edificar a educação em nível político, social e acadêmico, o que à luz da Teoria Crítica seria possível pelo pensar crítico-reflexivo, pois “[...] o pensar não passa pelo crivo das normas obrigatórias, mas sim pela consciência obrigatória de se colocar à disposição da crítica ${ }^{5 "}$ (ADORNO, 1986).

$\mathrm{O}$ ato de incluir pressupõe uma superação dos preconceitos vigentes na sociedade, sobretudo, rompendo com uma consciência engessada por estigmas. Ou seja, desbarbarizar tornou-se crucial na educação contemporânea, se reafirmando/construindo estruturas organizacionais democráticas na contemporaneidade. Pois, "é no olhar para o desviante, no ódio à banalidade, na busca do que ainda não está gasto, do que ainda não foi capturado pelo esquema conceitual geral, que reside a derradeira chance do pensamento" (ADORNO, 1993, p.58).

Há de se considerar que pensar no acolhimento de todos e não somente de uma parte da sociedade é determinante para, sobretudo, pensar/organizar, e, por conseguinte implementar uma sociedade justa, humana e solidária, visto que uma sociedade de

\footnotetext{
${ }^{5}$ Palestra feita para os acadêmicos da universidade técnica Kalrsruhe em 10 de novembrode 1953. Suas referências originais são: "Über Technik und Humanismus". In Gesammelte Schriften 20, Frankfurt am Main: Suhrkamp Verlag, 1986. Texto encontrado no endereço eletrônico: http://www.unimep.br/anexo/adm/13032015162121.pdf - Acesso em: 28/03/2020.
} 
emancipados deve considerar as demandas diversificadas, atendendo os indivíduos em suas subjetividades, pois:

[...] quem defende ideias contrários à emancipação, e, portanto, contrários à decisão consciente independente de cada pessoa em particular, é um antidemocrata, até mesmo se as ideais que correspondem a seus desígnios são difundidas no plano formal da democracia. (ADORNO, 1995, 142)

Adorno (1995) discorre que no plano formal da democracia existem possibilidades de contradições, visto que sua operacionalidade pode não estar trabalhando conforme seu conceito. Conceito este, que para ser de fato trabalhado, demanda pessoas emancipadas. $O$ autor explica que a única concretização da emancipação consiste em que as poucas pessoas interessadas nesta direção, foquem toda a sua energia para que a educação seja uma educação para a contestação e para a resistência.

A Teoria Crítica nos apresenta que para afirmação de uma educação emancipada, os protagonistas da transformação educativa necessitam também se afirmarem como sujeitos emancipados, ou seja, capazes de compreender o significado da democracia no ambiente educativo, e quiçá, social.

\section{REFERÊNCIAS}

ADORNO, T.W. Educação e emancipação. São Paulo: Paz e Terra, 1995.

Minima Moralia. Trad. de Luiz Eduardo Bicca. 2. ed. São Paulo: Ática, 1993.

ANDERSON, Perry. Balanço do neoliberalismo. In: SADER, Emir (Org.). PósNeoliberalismo: as políticas sociais e o Estado democrático. Rio de Janeiro: Paz e Terra, 1995. Pp 09-23.

BRASIL. Política Nacional de Educação Especial na perspectiva da Educação Inclusiva. Brasília: MEC/SEESP, 2008.

COSTA, Valdelúcia Alves da. Formação e Teoria Crítica da Escola de Frankfurt: trabalho, educação, indivíduo com deficiência. Niterói, EdUFF, 2005.

Educação escolar inclusiva: Demanda por uma sociedade democrática.

Revista Cadernos de Educação Especial: nº 22, pp.3, 2003.

Formação de professores e sua relação com a educação inclusiva: desafios à experiência teórica na práxis pedagógica. Revista Educação Especial, Santa Maria, v.28, n. 52, Pp. 405-416, maio/ago. 2015. Disponível em:

<http://dx.doi.org/10.5902/1984686X9628>. Acesso em: 15/02/2020. 
DAMASCENO, A. R. Educação Inclusiva e a Organização da escola: perspectivas críticas e desafios políticos do projeto pedagógico. Rio de Janeiro: Abrace um Aluno Escritor: CAPES, 2015.

HORKHEIMER, M. Teoria Tradicional e Crítica. Filosofia e Teoria crítica. São Paulo: Nova Cultural, 1991.

\&ADORNO, T. W. Dialética do esclarecimento: fragmentos filosóficos. Tradução de Guido Antonio de Almeida. Rio de Janeiro: Zahar.1985.

MORAES, M. C. M., DUAYER, M. A recelebração do mercado: repercussões nas ciências sociais e na história. 1995. (mimeog).

PEREIRA, A. S. Formação de professores para o atendimento educacional especializado (AEE): diálogos e fronteiras da educação especial á inclusão escolar em Nova Iguaçu/RJ. Trabalho de Conclusão de Curso apresentado como exigência para a obtenção da Graduação em Pedagogia pela Faculdade de Educação, Universidade Federal Rural do Rio de Janeiro, 2014.

SAWAIA, B. B. 1999. As Artimanhas da exclusão - Análise psicossocial e ética da desigualdade social. Rio de Janeiro, Editora Vozes.

SANTOS, M. A aceleração contemporânea: tempo mundo e espaço mundo. In: SANTOS, M., SOUZA, M. A., SCALARTO, F. C., ARROYO, M. (Orgs). Fim do século e Globalização. São Paulo: Hucitec, 1995. p.16-45.

THERBORN, G. A crise e o futuro do capitalismo. In: SADER, E., GENTILLI, P. (Orgs). Pós neoliberalismo: as políticas sociais e o Estado democrático. Rio de Janeiro: Paz e Terra, 1995. p. 39-53.

Recebido:06/05/2020

Aprovado: 08/07/2020 